\section{A population based study on health conditions associated with the use of benzodiazepines among older adults (The Bambuí Health and Aging Study)}

\author{
Estudo de base populacional sobre condições de \\ saúde associadas ao uso de benzodiazepínicos \\ em idosos (Projeto Bambuí)
}

\author{
${ }^{1}$ Núcleo de Estudos \\ em Saúde Pública e \\ Envelhecimento, Fundação \\ Oswaldo Cruz/Universidade \\ Federal de Minas Gerais, \\ Belo Horizonte, Brasil. \\ 2 Centro de Pesquisa René \\ Rachou, Fundação Oswaldo \\ Cruz, Belo Horizonte, Brasil. \\ 3 Faculdade de Medicina, \\ Universidade Federal de \\ Minas Gerais, Belo Horizonte, \\ Brasil. \\ Correspondence \\ M. F. Lima-Costa \\ Núcleo de Estudos em Saúde \\ Pública e Envelhecimento, \\ Fundação Oswaldo Cruzl \\ Universidade Federal de \\ Minas Gerais. \\ Av. Augusto de Lima 1715, \\ Belo Horizonte, $M G$ \\ 30190-002, Brasil. \\ lima-costa@cpqrr.fiocruz.br
}

\begin{abstract}
The aim of this study was to assess the health conditions and use of health services among elderly users of benzodiazepines. The study was carried out in the city of Bambui in Minas Gerais State, Brazil. Of 1,742 inhabitants aged over 60, 1,419 participated in the study. Information about benzodiazepine and the use of other medications was obtained by means of interviews and checking medication packaging. After adjustments for confounding variables, benzodiazepine remained significantly associated with poorer self reported health (prevalence ratio $=1.94$ and 2.04 for reasonable and bad/very bad health, respectively), common mental disorders (1.33), myocardial infarction (1.42), number of doctor visits in the previous 12 months (1.90 and 2.24 for $2-3$ and 4+ visits, respectively) and concomitant use of other medications (1.84 and 1.83 for 2-4 and $5+$ medications). The results showed that the factors associated with the use of benzodiazepine were similar to those observed in the elderly in higher income countries. The concomitant use of benzodiazepines and two or more medications was highly prevalent (59.5\%), characterizing a situation of risk, which deserves attention as a public health problem.
\end{abstract}

Benzodiazepines; Polypharmacy; Health Status; Aged
Jussara Mendonça Alvarenga 1,2 Antônio Ignácio de Loyola Filho 1,2 Josélia Oliveira Araújo Firmo 1,2 Maria Fernanda Lima-Costa 1,2,3 Elizabeth Uchoa 1,2,3

\section{Introduction}

Benzodiazepines were discovered in the 1950s and used for the treatment of anxiety and insomnia. Since then, they have largely been used to alleviate these symptoms, and also as an auxiliary medication in the treatment of several other conditions, such as depression, bipolar disturbance, schizophrenia, alcoholic abstinence and epilepsy. The use of benzodiazepines is greater among the elderly 1,2 . This has been a matter of concern because older subjects are more likely to present adverse health reactions, such as falling 3,4,5, cognitive deficit 6 and dependence 7 .

Population based studies have shown that, among the elderly, women represent the demographic characteristic most consistently associated with the use of benzodiazepines $2,8,9,10$. Some studies have described a higher consumption of the medication among the oldest old 9,11, but not all 8,10 . In general, worse health conditions are associated with the use of benzodiazepines, such as number of chronic diseases 12 , functional disability 13 , worse self-reported health 8,12 , coronary disease ${ }^{8}$, depressive symptoms $12,13,14$ and insomnia 14 . Furthermore, benzodiazepine users consult physicians with greater frequency 13,15 and consume greater amounts of other medications 12,14.

To our knowledge, there are few studies examining the covariates of the use of benzodiazepines among Brazilian elderly. A study carried out in a community center in Rio de Janeiro reported 
an association between the daily use of benzodiazepine and headache, insomnia, and the use of four or more other medications 16 . A population-based study, conducted among older adults living in the community (as part of the baseline of the Bambuí Health and Aging Study), reported an independent association between the use of benzodiazepines and the female gender; in this study age, marital status, number of years of schooling and monthly family income were not associated with use of the medication 10 .

The present study is part of the Bambuí Health and Aging Study, mentioned above, and aims to assess the health conditions and related aspects associated with the use of benzodiazepines in older adults living in the community.

\section{Methodology}

\section{Study area and population}

The Bambuí Health and Aging Study is a cohort study of older adults which has been carried out in the town of Bambuí (15,000 inhabitants), situated in the State of Minas Gerais, Brazil. A complete census of the city was carried out in November and December of 1996 for identification of participants. Among the residents aged 60 or more on 1st January, 1997, 1,606 (92.2\%) participated in the cohort baseline and were selected for the present study. From these, 1,419 were selected for this study because they had complete information for all the variables which were used. The reasons for non participation were need for a proxy respondent during the interview (90 subjects), and absence of laboratory examinations (97 subjects) due to refusals 17. Participants and non participants differed in relation to age and gender ( $p<0.05)$, but they were similar in relation to the prevalence of benzodiazepines use ( $p=0.393)$.

All the participants signed a post-informed consent form, and the Bambuí Health and Aging Study was approved by the Ethics Committee of the Fundação Oswaldo Cruz (FIOCRUZ), Rio de Janeiro.

\section{Study variables}

The dependent variable of the study is the use of benzodiazepines in the last 90 days. The information was obtained by standardized interviews and checking medication packaging. The medications were classified according to the Anatomical Therapeutic Chemical Index (ATC Index) 18.

The independent variables of the study included health conditions, use of health ser- vices and use of other medications. Among the former, the following were considered: general health (self-reported health), insomnia, common mental disorders, hypertension, angina pectoris, myocardial infarction and diabetes. Self-reported health was defined by the answer to the following question: "At this moment, do you consider your health to be very good, good, reasonable, bad or very bad?". Insomnia was defined as the presence of any difficulty to initiate sleeping or disrupted sleep or early morning awakening, at least three times a week in the previous 30 days, with the presence of any distress or interference with personal functioning in daily living, as described previously 19. Common mental disorders (depression and/or anxiety symptoms) were assessed by the General Health Questionnaire-12 (GHQ-12), using a cut-off of 4/5, which has been previously found to be more appropriate for the study population 20 .

Hypertension was considered as systolic blood pressure $\geq 140 \mathrm{mmHg}$ or systolic blood pressure $\geq 90 \mathrm{mmHg}$ or current treatment for hypertension 21. Diabetes mellitus was defined by fasting blood glucose level $\geq 126 \mathrm{mg} / \mathrm{dL}$ and/or current use of insulin or oral antidiabetic drug treatment 22 . The definition of angina was based on the Rose 23 questionnaire. The definition of myocardial infarction was based on the report of a previous medical diagnosis.

Use of health services in this study were considered as number of visits to a doctor in the previous 12 months and number of hospitalizations in the same period. Information on the use of other medications were obtained as described above; three categories were considered: "0-1 medications” (reference), "2-4 medications” (minor polypharmacy) and " $5+$ medications" (major polypharmacy) 24 .

The interviewers were performed by subjects with eleven or more complete years of schooling and they were trained by a qualified psychiatrist (E.U.).

\section{Statistical analysis}

The univariate and multivariate analyses were based on prevalence rates, estimated by robust Poisson regression 25 . A hierarchical theoretical approach was followed to implement the multivariate analysis 26 . The first model included general and mental health (self reported health, common mental disorders and insomnia). The second model included physical health (hypertension, diabetes mellitus, angina pectoris, and myocardial infarction). The third model included use of health services and medications (number of medical visits, hospitalization and number of 
medications in use, except benzodiazepines or number of other medications in use). The variables which reached $\mathrm{p}<0.05$ levels in the first model were kept in the subsequent models, and so forth for the subsequent levels. Those which remained associated with the use of benzodiazepines at $\mathrm{p}<0.05$ levels in the third model were retained in the final analysis (considered independently associated to the event). Gender and age were considered $a$ priori confounding variables in the study and were kept in all the multivariate models. The analyses were performed using Stata software, version 9.2 (Stata Corp., College Station, U.S.A.).

\section{Results}

Among the 1,419 participants of the study, the average age was 68.8 years (standard deviation $-\mathrm{SD}=7.0$ ), and the female gender predominated $(61.7 \%)$. The prevalence of the use of benzodiazepines in the study population was $22 \%$.

The results of the univariate analysis of the association between the use of benzodiazepines, age, gender, and general and mental health are shown in Table 1. All of these variables - except age - were significantly associated $(\mathrm{p}<0.05)$ with the use of benzodiazepines.
The use of benzodiazepines was significantly associated with hypertension, diabetes mellitus and medical diagnosis of myocardial infarction in the univariate analysis (Table 2).

The results of the univariate analysis of the association between use of benzodiazepines, use of health services and use of other medications are presented in Table 3. Significant prevalence ratios were found for the number of doctor visits in the previous 12 months (1, 2-3 and 4+ visits), hospitalizations and concomitant use of other medications (2-4 and 5+).

The results of the multivariate analysis of the factors associated with the use of benzodiazepines are presented in Table 4. After all adjustments (model 3), the female gender, worse self reported health, (reasonable and bad or very bad), common mental disorders, medical diagnosis of myocardial infarction, number of doctor visits in the last 12 months (2-3 and 4+ visits) and concomitant use of other medications (2-4 and $5+$ ) remained significantly associated with the use of benzodiazepines.

Table 1

Use of benzodiazepines among older adults, by gender, age, self-reported health and mental health. The Bambuí cohort baseline, Minas Gerais State, Brazil.

\begin{tabular}{|c|c|c|c|}
\hline Characteristics & Total participants $(n)$ & $\begin{array}{c}\text { Benzodiazepines } \\
\text { users (\%) }\end{array}$ & PR $(95 \% \mathrm{Cl})$ \\
\hline \multicolumn{4}{|l|}{ Gender } \\
\hline Male & 544 & 13.1 & 1.00 \\
\hline Female & 875 & 27.5 & $2.11(1.66-2.69)$ \\
\hline \multicolumn{4}{|l|}{ Age (years) } \\
\hline $60-69$ & 858 & 21.7 & 1.00 \\
\hline $70-79$ & 431 & 21.1 & $0.97(0.78-1.22)$ \\
\hline $80+$ & 130 & 26.9 & $1.24(0.91-1.69)$ \\
\hline \multicolumn{4}{|l|}{ Self-reported health } \\
\hline Very good or good & 346 & 8.1 & 1.00 \\
\hline Reasonable & 709 & 23.1 & $2.86(1.96-4.18)$ \\
\hline Bad or very bad & 364 & 33.0 & $4.07(2.77-5.98)$ \\
\hline \multicolumn{4}{|c|}{ Common mental disorders } \\
\hline No & 876 & 16.6 & 1.00 \\
\hline Yes & 543 & 30.8 & $1.86(1.53-2.26)$ \\
\hline \multicolumn{4}{|c|}{ Insomnia in the last 30 days } \\
\hline No & 868 & 17.9 & 1.00 \\
\hline Yes & 551 & 28.5 & $1.60(1.31-1.94)$ \\
\hline
\end{tabular}

PR (95\% Cl): crude prevalence ratio (95\% robust confidence interval). 
Use of benzodiazepines among older adults, by physical health. The Bambuí cohort baseline, Minas Gerais State, Brazil.

\begin{tabular}{|c|c|c|c|}
\hline Characteristics & Total participants $(n)$ & $\begin{array}{c}\text { Benzodiazepines } \\
\text { users (\%) }\end{array}$ & PR $(95 \% \mathrm{Cl})$ \\
\hline \multicolumn{4}{|l|}{ Hypertension } \\
\hline No & 542 & 17.2 & 1.00 \\
\hline Yes & 877 & 25.0 & $1.46(1.17-1.81)$ \\
\hline \multicolumn{4}{|l|}{ Diabetes mellitus } \\
\hline No & 1,207 & 21.0 & 1.00 \\
\hline Yes & 212 & 27.8 & $1.33(1.04-1.69)$ \\
\hline \multicolumn{4}{|l|}{ Angina pectoris } \\
\hline No & 1,288 & 21.7 & 1.00 \\
\hline Yes & 131 & 24.4 & $1.12(0.82-1.55)$ \\
\hline \multicolumn{4}{|c|}{ Myocardial infarction } \\
\hline No & 1,351 & 21.1 & 1.00 \\
\hline Yes & 68 & 39.7 & $1.88(1.38-2.57)$ \\
\hline
\end{tabular}

PR $(95 \% \mathrm{Cl})$ : crude prevalence ratio ( $95 \%$ robust confidence interval).

Table 3

Use of benzodiazepines among older adults, by use of health services and other medications. The Bambuí cohort baseline, Minas Gerais State, Brazil.

\begin{tabular}{|c|c|c|c|}
\hline Characteristics & Participants (n) & $\begin{array}{c}\text { Benzodiazepines } \\
\text { users (\%) }\end{array}$ & PR $(95 \% \mathrm{Cl})$ \\
\hline \multicolumn{4}{|c|}{ Number of doctor visits in the } \\
\hline \multicolumn{4}{|l|}{ last 12 months } \\
\hline 0 & 273 & 7.0 & 1.00 \\
\hline 1 & 298 & 13.8 & $1.98(1.18-3.32)$ \\
\hline $2-3$ & 404 & 24.8 & $3.56(2.23-5.67)$ \\
\hline $4+$ & 444 & 34.2 & $4.92(3.13-7.73)$ \\
\hline \multicolumn{4}{|c|}{ Hospital admittance in the } \\
\hline \multicolumn{4}{|l|}{ last 12 months } \\
\hline No & 1,119 & 19.0 & 1.00 \\
\hline Yes & 300 & 33.0 & $1.73(1.42-2.12)$ \\
\hline \multicolumn{4}{|c|}{ Number of other medications in } \\
\hline \multicolumn{4}{|c|}{ use, not including benzodiazepines } \\
\hline $0-1$ & 444 & 8.3 & 1.00 \\
\hline $2-4$ & 668 & 25.6 & $3.07(2.20-4.29)$ \\
\hline $5+$ & 307 & 33.9 & $4.07(2.88-5.75)$ \\
\hline
\end{tabular}

PR (95\% Cl): crude prevalences ratio ( $95 \%$ robust confidence interval). 
Results of the multivariate analyses of factors associated with the use of benzodiazepines among older adults. The Bambui cohort baseline, Minas Gerais State, Brazil.

\begin{tabular}{|c|c|c|c|}
\hline Variables & $\begin{array}{l}\text { Model } 1 \text { * } \\
\text { PR }(95 \% \mathrm{Cl})\end{array}$ & $\begin{array}{l}\text { Model } 2 \text { ** } \\
\text { PR }(95 \% \mathrm{Cl})\end{array}$ & $\begin{array}{l}\text { Model } 3 \text { *** } \\
\text { PR }(95 \% \mathrm{Cl})\end{array}$ \\
\hline Age & $1.00(0.99-1.01)$ & $1.00(0.99-1.02)$ & $1.00(0.98-1.01)$ \\
\hline Female gender (vs. male) & $1.81(1.42-2.31)$ & $1.80(1.42-2.29)$ & $1.48(1.16-1.89)$ \\
\hline \multicolumn{4}{|l|}{ Self-reported health (vs. good) } \\
\hline Reasonable & $2.46(1.68-3.60)$ & $2.41(1.64-3.54)$ & $1.94(1.32-2.85)$ \\
\hline Bad or very bad & $3.08(2.07-4.56)$ & $2.94(1.98-4.38)$ & $2.04(1.36-3.05)$ \\
\hline Common mental disorders (vs. no) & $1.38(1.12-1.69)$ & $1.43(1.18-1.75)$ & $1.33(1.09-1.62)$ \\
\hline Insomnia in the last 30 days (vs. no) & $1.13(0.92-1.39)$ & - & - \\
\hline Diabetes mellitus (vs. no) & - & $1.20(0.95-1.52)$ & - \\
\hline Angina pectoris (vs. no) & - & $0.92(0.68-1.25)$ & - \\
\hline Hypertension (vs. no) & - & $1.28(1.03-1.58)$ & $1.16(0.94-1.44)$ \\
\hline Myocardial infarction (vs. no) & - & $1.50(1.09-2.07)$ & $1.42(1.03-1.96)$ \\
\hline \multicolumn{4}{|l|}{ Number of doctor visits in the last 12 months (vs. none) } \\
\hline 1 & - & - & $1.37(0.82-2.30)$ \\
\hline $2-3$ & - & - & $1.90(1.16-3.11)$ \\
\hline $4+$ & - & - & $2.24(1.37-3.67)$ \\
\hline Hospital admittance in the last 12 months (vs. no) & - & - & $1.13(0.92-1.39)$ \\
\hline \multicolumn{4}{|c|}{ Number of medications in use, except for benzodiazepines (vs. < 1) } \\
\hline $2-4$ & - & - & $1.84(1.28-2.63)$ \\
\hline $5+$ & - & - & $1.83(1.24-2.70)$ \\
\hline
\end{tabular}

PR (95\% Cl): prevalence ratio (95\% robust confidence interval) adjusted for all variables listed in the column, and estimated using Poisson regression.

* General and mental health;

** General and mental health plus physical health;

$\star \star \star$ General, mental and physical health plus use of health services and medications.

\section{Discussion}

The results of this study showed that the use of benzodiazepines in older adults was independently associated with worse general health conditions (self-reported health), mental health (common mental disorders), physical health (medical history of myocardial infarction), use of health services (number of doctor's visits) and the concomitant use of other medications.

The variable which showed the strongest association with the use of benzodiazepines was the number of doctor visits in the previous 12 months. This finding is similar to that observed in studies conducted in Australia 15 and in the United States 13. The explanation for this association is evident because the benzodiazepines can only be dispensed with a medical prescription.

The use of benzodiazepines and the concomitant use of other medications increases the risk of adverse reactions and interactions 27,28 . In this study, as observed in previous ones 12,14, the use of benzodiazepines was independently associated with the concomitant use of other medications; in the Bambuí Health and Aging Study population, $96.6 \%$ of benzodiazepines users were also using other medications (not shown).

Among the health conditions considered in this study, worse self-reported health showed the strongest association with the use of benzodiazepines. Self-reported health is a global indicator of health, which reflects the physical, mental and social well-being of older subjects 29 . Furthermore, it has been found to be a robust predictor of mortality in different countries and cultures 30 . The association between worse self-reported health and the use of benzodiazepines observed in the present study is consistent with other findings 8,12. Possible explanations for this association include: (1) worse self-reported health has a negative impact on mental health, leading to a greater use of benzodiazepines and/or (2) a negative evaluation of one's own health could result from health problems due to the prolonged use of this medication 31 .

A greater use of benzodiazepine by older adults with depressive symptoms has been consistently described 12,13,14. Our results are in agree- 
ment with these observations. The use of benzodiazepine was associated with common mental disorders, independently of physical health and other health related conditions. The association between common mental disorders and the use of benzodiazepines found in this study suggests a misuse of benzodiazepines.

Another factor found to be associated with the use of benzodiazepines in the present study was myocardial infarction. An explanation for this association is that benzodiazepines might be used for the treatment of anxiety caused by the experience of getting ill 8,12.

An association between the female gender and use of benzodiazepines among the Bambuí Health and Aging Study population was described previously ${ }^{10}$. The results of the present study add to those from the earlier study to show that this association persists even after adjustments for mental and physical health, as well as for the use of health services.

Some advantages and limitations of this study deserve further comment. The study was carried out among older adults living in the community. Population-based studies are less prone to selection bias than studies conducted in selected pop-

\section{Resumo}

O objetivo deste estudo foi determinar condições de saúde e usos de serviços de saúde associados ao uso de benzodiazepínicos entre idosos. O estudo foi conduzido na cidade de Bambuí, Minas Gerais, Brasil. Entre os 1.742 residentes com idade $\geq 60$ anos, 1.419 participaram do estudo. Informações sobre o uso de benzodiazepínicos e de outros medicamentos foram obtidas por meio de entrevista e verificação da embalagem. Após ajustamentos por variáveis de confusão, o uso de benzodiazepínicos permaneceu significativamente associado com pior auto-avaliação da saúde (razões de prevalência $=1,94$ e 2,04 para razoável e ruim/muito ruim, respectivamente), transtornos mentais comuns $(1,33)$, infarto do miocárdio $(1,42)$, número de visitas ulations. The information about benzodiazepine use was obtained by means of interviews and by reviewing the medication packages or prescriptions, thus decreasing the probability of misinformation. On the other hand, the cross-sectional nature of this study does not allow for the assessment of temporal relationships between health conditions and benzodiazepine use, which is one of the limitations of this present study. Another limitation is the generalizability of the results. This study was conducted in an old population living in a small city. Because there are no previous population based studies examining health conditions associated with benzodiazepine use in this country, it is not possible to compare our results with those obtained in older adults living in other large or small Brazilian cities.

In spite of these limitations, our results showed that the factors associated with the use of benzodiazepine in the elderly living in Bambuí were similar to those observed in the elderly in higher income countries. The concomitant use of benzodiazepines and two or more medications was highly prevalent (59.5\%), suggesting a situation of risk, which is cause for concern among those working with public health. médicas nos últimos 12 meses (1,90 e 2,24 para 2-3 $e$ $4+$ visitas, respectivamente) e uso concomitante de outros medicamentos $(1,84$ e 1,83 para 2-4 e 5+ medicamentos). Os resultados mostraram que os fatores associados ao uso de benzodiazepinicos foram semelhantes aos observados em idosos de países com renda mais alta. O uso concomitante de benzodiazepínicos e de outros dois ou mais medicamentos foi freqüente (59,5\%), caracterizando uma situação de risco que merece atenção como problema de saúde pública.

Benzodiazepinas; Polimedicação; Nível de Saúde; Idoso 


\section{Contributors}

J. M. Alvarenga designed the study and participated in writing up the article and data analysis. A. I. Loyola Filho was involved in writing the article, data analysis and revision of the final text. J. O. A.Firmo coordinated the data collection and revised the final text. M. F. LimaCosta was co-responsible for study orientation, participated in the writing of the article, provided guidance on data analysis and revised the final version. E. Uchoa also provided study orientation, supported writing the text and was responsible for revising the final version of the article.

\section{Acknowledgments}

M. F. Lima-Costa and E. Uchoa are fellows of the Brazilian Council for Scientific and Technological Development (CNPq).

\section{References}

1. Lima MS, Hotopf M, Mari JJ, Béria JU, Bastos AB, Mann A. Psychiatric disorder and the use of benzodiazepines: an example of the inverse care law from Brazil. Soc Psychiatr Epidemiol 1999; 34: 316-22.

2. Laganoui R, Depont F, Fourrier A, Abouelfath A, Bégaud B, Verdoux H, et al. Patterns and correlates of benzodiazepine use in the French general population. Eur J Clin Pharmacol 2004; 60:523-9.

3. Coutinho ESF, Silva SD. Uso de medicamentos como fator de risco para fratura grave decorrente de queda em idosos. Cad Saúde Pública 2002; 18:1359-66.

4. Rozenfeld S, Camacho LAB, Veras RP. Medication as a risk factor for falls in older women in Brazil. Rev Panam Salud Pública 2003; 13:369-75.

5. Landi F, Onder G, Cesari M, Barillaro C, Russo A, Bernabei R, et al. Psychotropic medications and risk falls among community-dwelling frail older people: an observational study. J Gerontol A Biol Sci Med Sci 2005; 60:622-6.
6. Paterniti S, Dufouil C, Alperovitch A. Long-term benzodiazepine use and cognitive decline in the elderly: the Epidemiology of Vascular Aging Study. J Clin Psychopharmacol 2002; 22:285-93.

7. Madhusoodanan S, Bogunovic OJ. Safety of benzodiazepines in the geriatric population. Expert Opin Drug Saf 2004; 3:485-93.

8. Gleason PP, Schulz R, Smith NL, Newsom JT, Kroboth PD, Kroboz FJ, et al. Correlates and prevalence of benzodiazepine use in community-dwelling elderly. J Gen Intern Med 1998; 13:243-50.

9. Tu K, Mamdani MM, Hux JE, Tu J. Progressive trends in the prevalence of benzodiazepine prescribing in older people in Ontario, Canada. J Am Geriatr Soc 2001; 49:1341-5.

10. Alvarenga JM, Loyola Filho AI, Firmo JOA, LimaCosta MFF, Uchoa E. Prevalence and sociodemographic characteristics associated with benzodiazepines use among community dwelling older adults: the Bambuí Health and Aging Study (BHAS). Rev Bras Psiquiatr 2008; 30:7-11. 
11. Egan M, Moride Y, Wolfson C, Monette J. Longterm continuous use of benzodiazepines by older adults in Quebec: prevalence, incidence and risk factors. J Am Geriatr Soc 2000; 48:811-6.

12. Fourrier A, Letenneur L, Dartigues JF, Moore N, Bégaud B. Benzodiazepine use in an elderly community-dwelling population. Eur J Clin Pharmacol 2001; 57:419-25.

13. Blazer D, Hybels C, Simonsick E, Hanlon JT. Sedative, hypnotic, and antianxiety medication use in an aging cohort over ten years: a racial comparison. J Am Geriatr Soc 2000; 48:1073-9.

14. Mayer-Oakes A, Kelman G, Beers MH, Jong F, Matthias R, Atchison KA, et al. Benzodiazepine use in older, community-dwelling southern Californians: prevalence and clinical correlates. Ann Pharmacother 1993; 27:416-21.

15. Jorm AF, Grayson D, Creasey H, Waite L, Broe GA. Long-term benzodiazepine use by elderly people living in the community. Aust N Z J Public Health 2000; 24:7-10.

16. Huf G, Lopes CS, Rozenfeld S. O uso prolongado de benzodiazepines em mulheres de um centro de convivência para idosos. Cad Saúde Pública 2000; 16:351-62.

17. Lima-Costa MFF, Uchoa E, Guerra HL, Firmo JOA, Vidigal PG, Barreto SM. The Bambuí health and ageing study (BHAS): methodological approach and preliminary results of a population-based cohort study of the elderly in Brazil. Rev Saúde Pública 2000 ; 34:126-35.

18. World Health Organization. Anatomical Therapeutical Chemical (ATC) classification index with defined daily doses (DDDs). http://www.whocc.no/ atcddd/indexdatabase/ (accessed on Jan/2007).

19. Rocha FL, Guerra HL, Lima-Costa MFF. Prevalence of insomnia and associated sociodemographic factors in a Brazilian community: the Bambuí study. Sleep Med 2002; 3:121-6.

20. Costa E, Barreto SM, Uchoa E, Firmo JOA, LimaCosta MF, Prince M. Is the GDS-30 better than the GHQ-12 for screening depression in elderly people in the community? The Bambui Health Aging Study (BHAS). Int Psychogeriatr 2006; 18:493-503.
21. Chobanian AV, Bakris GL, Black HR, Cushman WC, Green LA, Izzo Jr. JL, et al. The Seventh Report of the Joint National Committee on Prevention, Detection, Evaluation, and Treatment of High Blood Pressure: the JNC 7 report. JAMA 2003; 289:2560-72.

22. Genuth S, Alberti KG, Bennett P, Buse J, Defronzo R, Kahn R, et al. Follow-up report on the diagnosis of diabetes mellitus. Diabetes Care 2003; 26:3160-7.

23. Rose GA. The diagnosis of ischemic heart pain and intermittent claudication in field surveys. Bull World Health Organ 1962; 27:645-58.

24. Bjerrum L, Sogaard J, Hallas J, Kragstrup J. Polypharmacy: correlations with sex, age and drug regimen. Eur J Clin Pharmacol 1998; 54:197-202.

25. Zou G. A modified regression approach to prospective studies with binary data. Am J Epidemiol 2004; 159:702-6.

26. Victora C, Huttly SR, Fuchs SC, Olinto MTA. The role of conceptual frameworks in epidemiological analysis: a hierarchical approach. Int J Epidemiol 1997; 26:224-7.

27. Llorente MD, David D, Golden AG, Silverman MA. Defining patterns of benzodiazepine use in older adults. J Geriatr Psychiatry Neurol 2000; 13:150-60.

28. Tamblyn R. Medication use in seniors: challenges and solutions. Therapie 1996; 51:269-82.

29. Lima-Costa MF, Firmo JOA, Uchoa E. A estrutura da auto-avaliação da saúde entre idosos: projeto Bambuí. Rev Saúde Pública 2004; 38:827-34.

30. Idler EL, Benyamini Y. Self-rated health and mortality: a review of twenty-seven community studies. J Health Soc Behav 1997; 38:21-37.

31. Voyer P, Cohen D, Lauzon S, Collin J. Factors associated with psychotropic drug use among community-dwelling old persons: a review of empirical studies. BMC Nurs 2004; 3:3. http://www.biomed central.com/1372-6955/3/3.

Submitted on 11/Dec/2007

Final version resubmitted on 24/Mar/2008

Approved on 16/Apr/2008 